\title{
EVALUATION OF SPATIOTEMPORAL CHARACTERISTICS OF PRECIPITATION EXTREMES VARIATIONS IN AMUR RIVER BASIN
}

\author{
YAN, B. ${ }^{1}-$ XU, J. ${ }^{1}-$ WANG, Y. $^{1 *}-$ HUANG, F. ${ }^{2}-$ HAN, X. ${ }^{1}-$ ZHANG, L. ${ }^{3}-$ GUO, L. ${ }^{4}$ \\ ${ }^{I}$ Changjiang River Scientific Research Institute, Changjiang Water Resources Commission of \\ the Ministry of Water Resources of China, Wuhan 430015, China \\ ${ }^{2}$ College of Hydrology and Water Resources, Hohai University, Nanjing 210098, China \\ ${ }^{3}$ School of Natural Resources, University of Nebraska-Lincoln, Lincoln, NE 68588, USA \\ ${ }^{4}$ Business School of Hohai University, Nanjing 210098, China \\ *Corresponding author \\ e-mail:wangyq@mail.crsiri.cn; phone: +86-158-5066-0117
}

(Received 1t Mar 2019; accepted 21 $1^{\text {st }}$ May 2019)

\begin{abstract}
Between 25th July and 19th August 2013, Amur River basin received some of its most extreme precipitation on record. The floods caused by the heavy rain brought affected Amur River and its 4 major tributaries. Hailun and Hailar stations break daily maximum precipitation record with $153.6 \mathrm{~mm}$ in 30th July, and $85.8 \mathrm{~mm}$ in 27th July, respectively. Based on daily precipitation observations at 25 stations from 1954 to 2014, the trends, periodicities and abrupt changes of five extreme precipitation indices in Amur River basin were investigated to the Spatiotemporal Characteristics of the extreme precipitation. Areaaveraged annual total wet-day precipitation (PRCPTOT), maximum 1-day precipitation amount (Rx1day), maximum 5-day precipitation amount (Rx5day), very wet days (R95) and extremely wet days (R99) had non-significant trends. By wavelet analysis for annual PRCPTOT, Rx1day, Rx5day, R95 and R99 series, the real part wavelet phase of main periods were mostly located at positive peaks in 2013, which were corroborated by abrupt change analysis. Multi-cycle superimposition of main periods is possibly the main cause for extreme precipitation in 2013. The record-breaking daily precipitation data improve 100-year recurrence interval $(111.47 \mathrm{~mm})$ to $130.61 \mathrm{~mm}$ in Hailun and raise 100-year recurrence interval from $78.95 \mathrm{~mm}$ to $87.91 \mathrm{~mm}$ in Hailar.
\end{abstract}

Keywords: precipitation extremes trend analysis wavelet analysis abrupt change Amur River basin

\section{Introduction}

Climate change is a severe issue all around the world, which received a lot of attention. The studies in the mean value for temperature and precipitation have made very rich and detailed achievements in different regions, such as China (Qian and Zhu, 2001; Shi et al., 2007), Italy (Moonen et al., 2002), Iran (Tabari and Talaee, 2011), Chile (Kumar et al., 1992), and South Africa (Minetti et al., 2003). The extreme climate events always accompanied by the disasters and the life and property losses directly (Easterling et al., 2000a; Changnon et al., 2000; Griggs and Noguer, 2002), attracts more and more interests of international organizations and scientific research personnel in recent years (Allen et al., 2015; Bordi et al., 2007; Furió and Meneu, 2011). Extreme events, generally defined as the extreme low or high values in the range of observation data (Field et al., 2012), are considered more important and necessary than the study of the mean values referred to human and natural system (Aguilar et al., 2009; Katz and Brown, 1992). As climate changes present poor-rich effects on different regions, the 
intensity and frequency of the extreme events also show different variation characteristics on geographically. In particular, the extreme precipitation indices present both negative and positive trends in India (Revadekar and Preethi, 2012; Preethi et al., 2011) and China (Wang and Zhou, 2005; Fu et al., 2013). It is generally that the changes in precipitation is the result of global atmospheric circulation in large spatial and temporal scales (Trenberth, 1999), and easily affected by monsoon (Li and Liu, 2006; Turner and Slingo, 2009), the Arctic Oscillation (Scaife et al., 2008), El Niño (Easterling et al., 2000b; DeFlorio et al., 2013) and other factors in the small term, but the relations between extreme indices and these factors are not the focus in our analyses and detailed research will be considered in future.

As one of the most important international rivers in East Asia with plenty of water, vast area and diversity of ecological features, Amur River has been concerned universally. The main factor caused the 2013 flood is the big amount of moisture poured on the Amur River basin, influenced by the East Asian monsoon, the Siberia High, high-pressure of the Pacific Ocean, the Arctic oscillation (AO) and so on (DanilovDanil'yan and Gel'fan, 2014). Therefore, it is necessary to explore the spatiotemporal characteristics of the extreme precipitation events and take measures to cut back the damage from the events.

The five extreme precipitation indices were chosen to identify the changes of extreme precipitation events firstly: PRCPTOT, Rx1day, Rx5day, R95 and R99, which were recommended by World Meteorological Organization (WMO), United Nations Environment Programme (UNEP), et al. (Tao et al., 2018; Li et al., 2018). Secondly, the Mann-Kendall test was used to calculate the magnitude of the trends for five extreme indices, and evaluate whether the trend is significant or not. Then the periodicities of the extreme indices were analyzed by wavelet transform, and the abrupt changes were detected by Mann-Kendall method. Compared with the results of the trends and periodicities, the changes of the five extreme indices time series were analyzed, and the changes could partly reveal the causes of the 2013 extreme precipitation. Finally, the extent of the 2013 extreme precipitation was measured by analyzing the typical station, and some conclusions were given. This paper aims to provide a reference for international river-related countries to deal with extreme weather events through the study of extreme precipitation in the Amur River Basin.

\section{Study area and data}

\section{Study area}

The Amur River (Fig. 1), with the other name as Heilong River in Chinese, has the tenth largest basin area on earth (Nicholson et al., 2014). The Amur River basin has an area of 1.86 million $\mathrm{km}^{2}$ which covers the territories of Mongolia, Russia, China and North Korea. In addition to its transboundary location, the Amur River basin can be characterized by contrasts between other geographic aspects: Russia and Asia; continental and monsoon climates; and southern dense and northern sparse populations. The climate of eastern Amur basin is humid monsoon temperature climate, which impact can reach the northernmost latitude on earth (Semenov et al., 2014; Yu et al., 2013). The climate of areas in the west of this basin (upper reach of the Amur River) is sheltered from monsoon influence and arid. The arid western portion of this basin is smaller compared with the more humid eastern portion. 


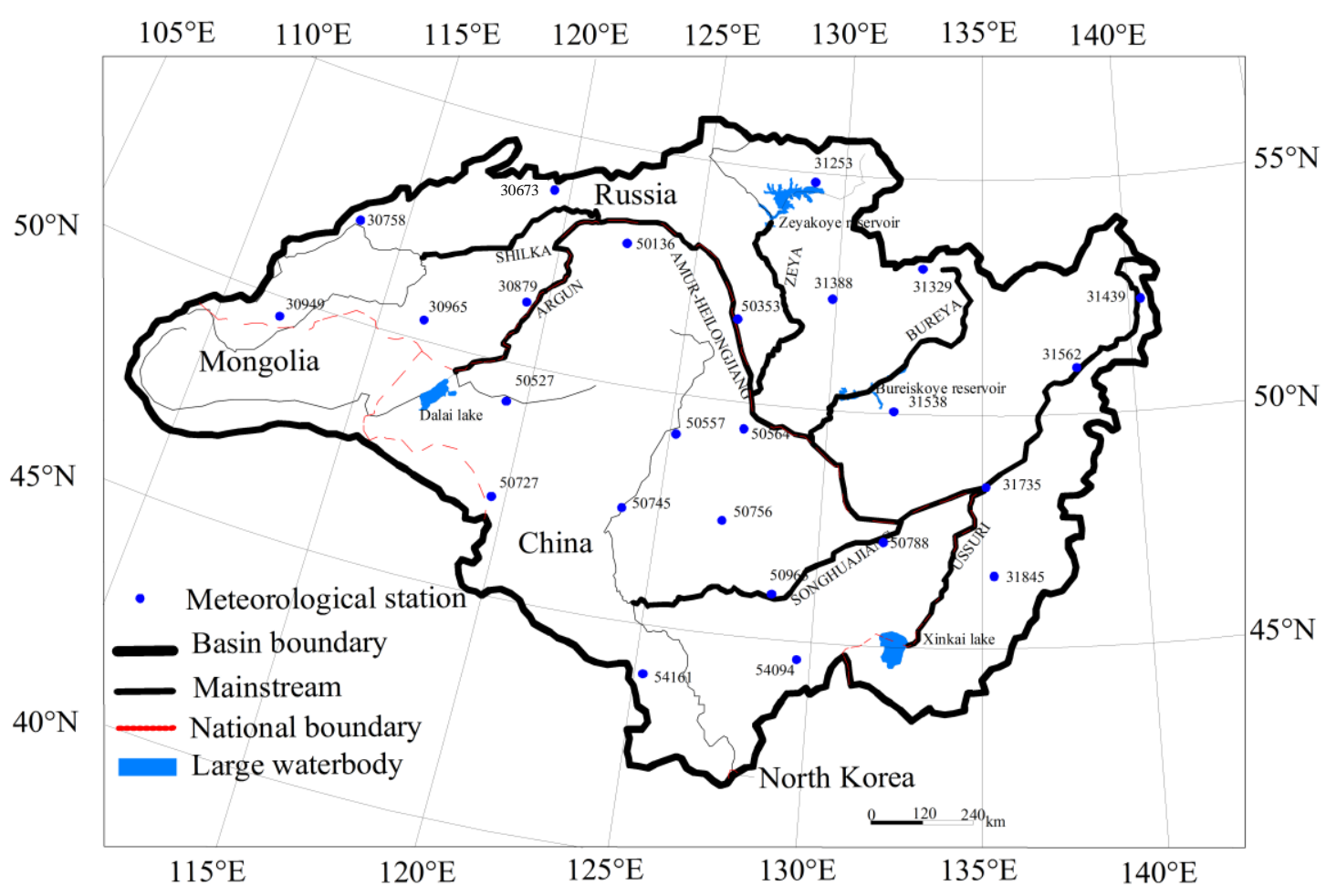

Figure 1. Locations of the 25 meteorological stations in the Amur River basin

\section{Long-term observed precipitation data}

The daily precipitation data from 1954 to 2014 were collected in 25 stations of which the 12 stations in China and 13 stations in Russia. Figure 1 presented the geographical location of the stations and more information were shown in Table 1. The Chinese station data was provided from the National Climate Center, China Meteorological Administration, and the station data of Russia came from Russian Federal Service for Hydrometeorology and Environmental Monitoring. The data collected from authoritative departments in China and Russia are measured daily data of meteorological sites. Data quality control is necessary in the calculation and detecting the trends and periodicities of the extreme precipitation indices (Huang et al., 2013; You et al., 2014), although these data has been detected by primary quality control. The RHtestV.4 software package (http://etccdi.pacificclimate.org/software.shtml) was employed for homogeneity assessment (Wang, 2008a, b; Wang and Feng, 2013).

\section{Methodology}

In this study, five indices were chosen for variations evaluation of the extreme precipitation in Amur River basin, the definitions of these indices were presented in Table 2, and all these indices are from the core indices which were recommended by the Joint CCI-CLIVAR Expert Team for Climate Change Detection Monitoring and Indices (ETCCDMI) and applied in different countries (Liu et al., 2015; Altinsoy et al., 2013). These indices were used widely to study the variations of extreme climate events in many regions of the world. 
Table 1. List of 25 stations used in the study

\begin{tabular}{c|c|c|c|c}
\hline WMO number & Station & Latitude $\left({ }^{\circ} \mathbf{N}\right)$ & Longitude $\left({ }^{\circ} \mathbf{E}\right)$ & Altitude (m) \\
\hline 30673 & Mogoca & 53.75 & 119.73 & 624 \\
30758 & Chita & 52.08 & 113.48 & 671 \\
30879 & Nerchinskij Zavod & 51.32 & 119.62 & 621 \\
30949 & Kyra & 49.57 & 111.97 & 907 \\
30965 & Borzja & 50.40 & 116.52 & 675 \\
31253 & Bomnak & 54.72 & 128.87 & 365 \\
31329 & Ekimchan & 53.08 & 132.98 & 540 \\
31388 & Norsk & 52.35 & 129.92 & 207 \\
31439 & Bogorodskoe & 52.38 & 140.47 & 33 \\
31538 & Sutur & 50.07 & 132.13 & 343 \\
31562 & Nizhnetambovskoe & 50.93 & 138.18 & 20 \\
31735 & Habarovsk & 48.57 & 135.17 & 75 \\
31845 & Krasnyj Jar & 46.53 & 135.32 & 128 \\
50136 & Mohe & 52.97 & 122.52 & 433 \\
50353 & Huma & 51.72 & 126.65 & 177 \\
50527 & Hailar & 49.27 & 119.75 & 610 \\
50557 & Nenjiang & 49.17 & 125.23 & 242 \\
50564 & Sunwu & 49.43 & 127.35 & 235 \\
50727 & Aershan & 47.17 & 119.93 & 997 \\
50745 & Qiqihar & 47.38 & 123.92 & 147 \\
50756 & Hailun & 47.43 & 126.97 & 239 \\
50788 & Fujin & 47.23 & 131.98 & 66 \\
50963 & Tonghe & 45.97 & 128.73 & 109 \\
54094 & Mudanjiang & 44.57 & 129.60 & 241 \\
54161 & Changchun & 43.90 & 125.27 & 237 \\
\hline
\end{tabular}

Table 2. Definitions of five precipitation indices

\begin{tabular}{c|c|c|c}
\hline Index & Indicator name & Definitions & Units \\
\hline PRCPTOT & Annual total wet-day precipitation & Annual total PRCP in wet days (RR $\geq 1 \mathrm{~mm})$ & $\mathrm{mm}$ \\
Rx1day & Max 1-day precipitation amount & Monthly maximum 1-day precipitation & $\mathrm{mm}$ \\
Rx5day & Max 5-day precipitation amount & Monthly maximum consecutive 5-day precipitation & $\mathrm{mm}$ \\
R95 & Very wet days & Annual total PRCP when RR > 95th percentile & $\mathrm{mm}$ \\
R99 & Extremely wet days & Annual total PRCP when RR > 99th percentile & $\mathrm{mm}$ \\
\hline
\end{tabular}

The RClimDex software was employed to carry out the calculation of extreme precipitation indices. The non-parametric Mann-Kendall test (Ahmad et al., 2015; Yin et al., 2016; Yue et al., 2002) was used to estimate the magnitude of indices trend and verify whether the trend is significant. The Kendall slope is computed as Equation 1:

$$
\beta=\operatorname{Median}\left(\frac{x_{i}-x_{j}}{i-j}\right)
$$

Where $1<j<i<\mathrm{n}$ and $\beta$ indicates the trend rate, and the unit is $\mathrm{mm} / \mathrm{year}$ in this study. The threshold of significance test was set to 0.05 when assessing the trends of extreme indices. 
Wavelet analysis (Lau and Weng, 1995), as an effective method to detect the periodicity in time series, was used to explore the extreme precipitation indices time series. In this study, Morlet wavelet was as the mother wavelet, to participate in the wavelet transform (Liu et al., 2015; Dai et al., 2003). The original data should be z-score standardized to eliminate the randomness before wavelet transform. The continuous transform is computed as Equations 2-4:

$$
\begin{gathered}
W_{f}(a, b)=|a|^{-\frac{1}{2}} \int_{-\infty}^{+\infty} f(t) \bar{\psi}\left(\frac{t-b}{a}\right) d t \\
\psi(t)=e^{i c t} e^{-t^{2} / 2} \\
\operatorname{Var}(a)=\int_{-\infty}^{+\infty}\left|W_{f}(a-b)\right|^{2} d b
\end{gathered}
$$

Where $f(t)$ is the extreme precipitation indices times series, $W_{f}(a, b)$ is the coefficient of wavelet transform, a and b are scale and time parameters, respectively. $\psi(t)$ is the morlet wavelet function, and $\operatorname{Var}(a)$ reveals the fluctuations of $a$ in the annual indices series. When $c=6.2$, the periodicity $T \approx a$, so $c$ was set to 6.2 in this study. By the graph of $\operatorname{Var}(a)$ varying with $a$, the main periodicities can be marked by the peaks corresponding to $a$.

The generalized extreme value distribution (GEV) (Furió and Meneu, 2011; Burke et al., 2010), derived from the characterization of extreme event, was employed to fit the annual Rx1day series. The distribution formula is computed as Equation 5:

$$
G(z ; \mu, \theta, \sigma, \xi)=\exp \left\{-\left[1+\xi\left(\frac{z-\mu}{\sigma}\right)\right]^{-1 / \xi}\right\}
$$

Defined on $\{\mathrm{z}: 1+\xi(\mathrm{z}-\mu) / \sigma>0\},-\infty<\mu<\infty$ (location parameter), $\sigma>0$ (scale parameter) and $-\infty<\xi<\infty$ (shape parameter). The profile likelihood method is more reasonable to be used to estimate the multi-year return levels and 0.95 confidence intervals, compared with the maximum likelihood method (Huang et al., 2013).

\section{Results and discussion}

\section{General characteristics of precipitation extreme indices}

The changes of Percentage of precipitation anomalies in the area-averaged time series for five extreme precipitation indices were shown in Figure 2, and the basic statistical data was performed in Table 3. The changes of 5 indices are almost consistent, while the R99 fluctuate severely. The anomaly percentage of R99 varies from 73.50 to -80.76 , while other indices fluctuate between -30 and 30 . In particular, the variation coefficient (0.30) of R99 is largest, while PRCPTOT, Rx1day, Rx5day, and R95 are $0.10,0.08,0.09$ and 0.18 , respectively.

Figure 3 shows the distribution for the multi-year mean of extreme precipitation indices from 1954 to 2014 in the Amur River basin. Most of the extreme precipitation events generally occurred in the southeast of the Amur River basin, while the south area 
are higher than other area for Rx1day. Spatially, the maximum value of the multi-year mean of extreme precipitation indices generally occurs in the south, while the minimum value generally occurs in the north. Specifically, the maxima of PRCPTOT, R95 and R99 occur in Krasnyj Jar Station (southeast of the basin), and the maxima of Rx1day and Rx5day occur in Changchun Station (southwest of the basin). The minima of PRCPTOT, Rx5day, R95 and R99 occur in Kyra Station (northwest of the basin), and the minimum value of Rx1day occurs in Mogoca Station (northwest of the basin). Particularly, the distributions are similar to the distribution pattern of the annual precipitation in Liu's view, although his study area is just one part of the Amur River basin (Liu et al., 2015).

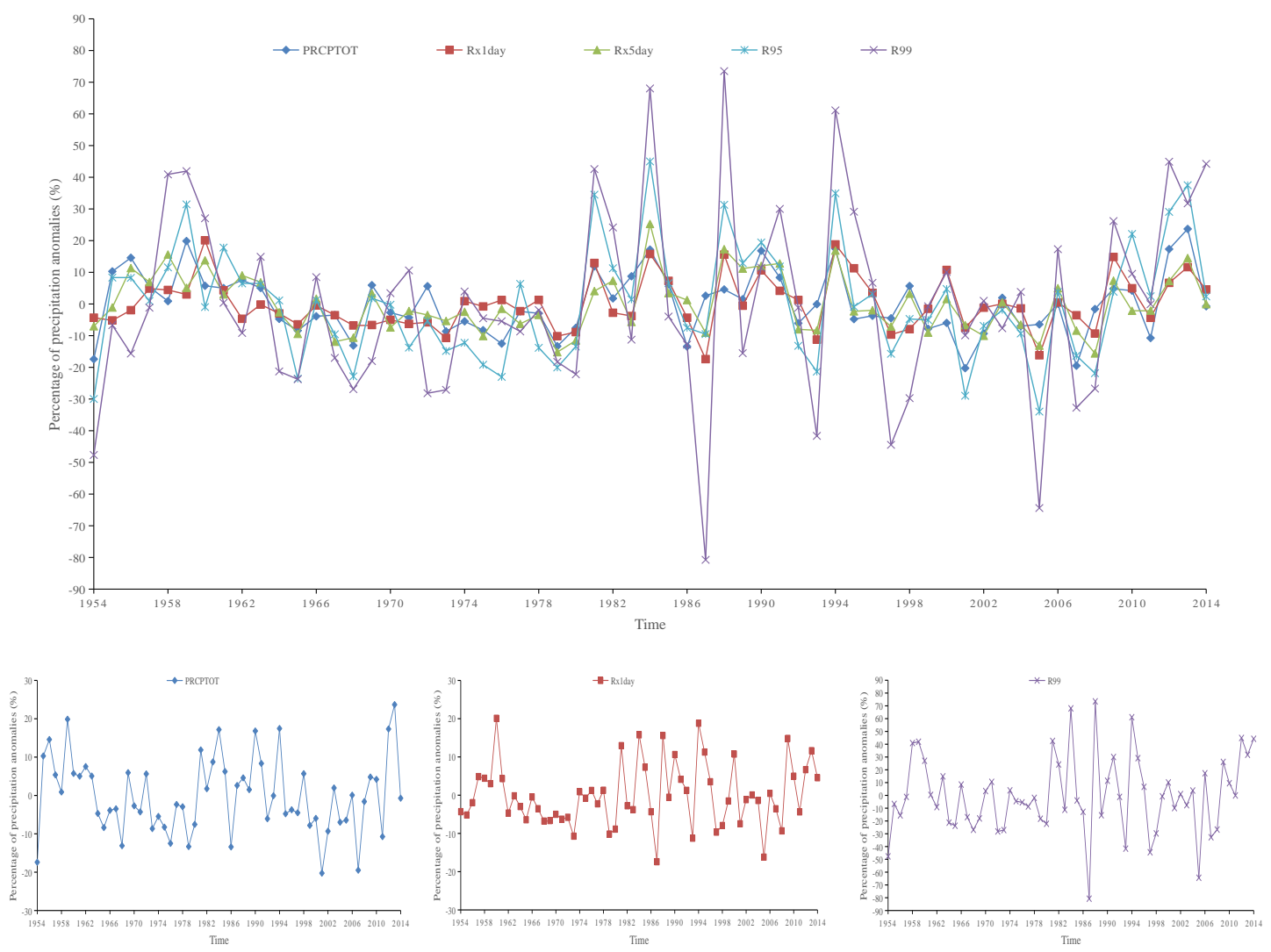

Figure 2. Percentage of precipitation anomalies changes in the time series for five extreme precipitation indices during 1954 to 2014 (comparison with the averages of 1954 2014). (PRCPTOT-annual total wet-day precipitation, Rxlday-maximum 1-day precipitation amount, Rx5day-maximum 5-day precipitation amount, R95-very wet days, R99-extremely wet days)

Table 3. Statistical information for five extreme precipitation indices time series

\begin{tabular}{c|c|c|c|c|c|c|c|c}
\hline Indices & $\begin{array}{c}\text { Mean } \\
(\mathbf{m m})\end{array}$ & $\begin{array}{c}\text { Standard } \\
\text { deviation }\end{array}$ & $\begin{array}{c}\text { Coefficient of } \\
\text { kurtosis }\end{array}$ & $\begin{array}{c}\text { Coefficient of } \\
\text { variation }\end{array}$ & $\begin{array}{c}\text { Maxima } \\
(\mathbf{m m})\end{array}$ & $\begin{array}{c}\text { Minima } \\
(\mathbf{m m})\end{array}$ & $\begin{array}{c}\text { Range } \\
\mathbf{( m m})\end{array}$ & $\begin{array}{c}\text { Range/ } \\
\mathbf{m} \\
(\boldsymbol{\%})\end{array}$ \\
\hline PRCPTOT & 500.69 & 49.16 & -0.19 & 0.10 & 619.28 & 399.27 & 220.01 & 43.94 \\
Rx1day & 46.84 & 3.86 & 0.03 & 0.08 & 56.26 & 38.7 & 17.56 & 37.49 \\
Rx5day & 78.86 & 7.19 & -0.26 & 0.09 & 98.79 & 66.56 & 32.23 & 40.87 \\
R95 & 124.75 & 22.24 & -0.05 & 0.18 & 180.88 & 82.38 & 98.50 & 78.96 \\
R99 & 39.66 & 11.91 & 0.54 & 0.30 & 68.81 & 7.63 & 61.18 & 154.26 \\
\hline
\end{tabular}




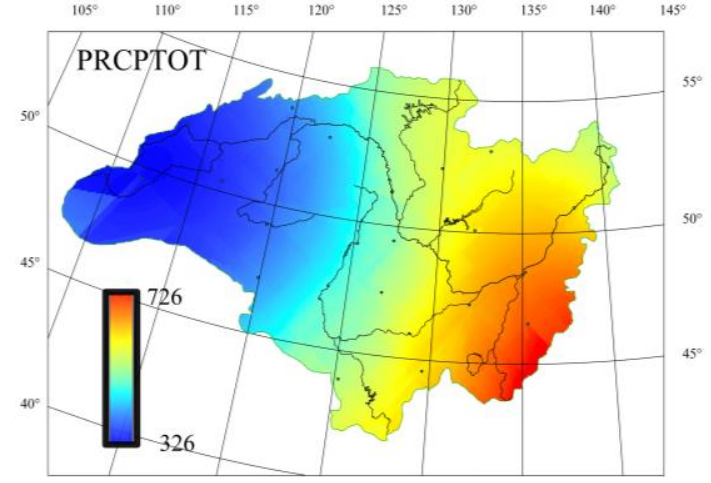

(a)

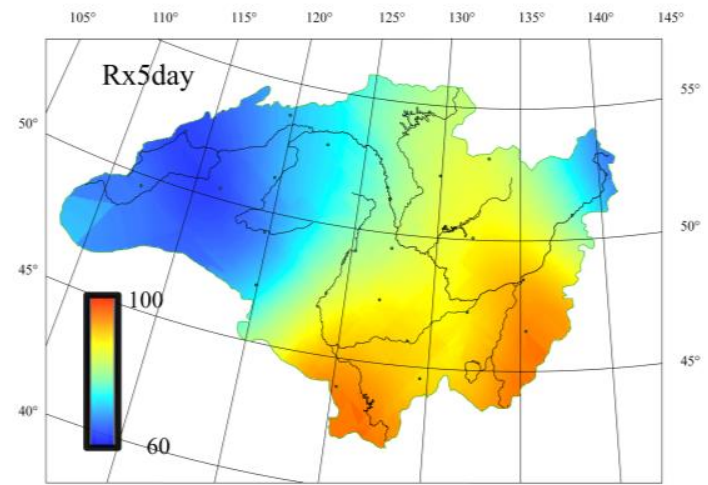

(c)

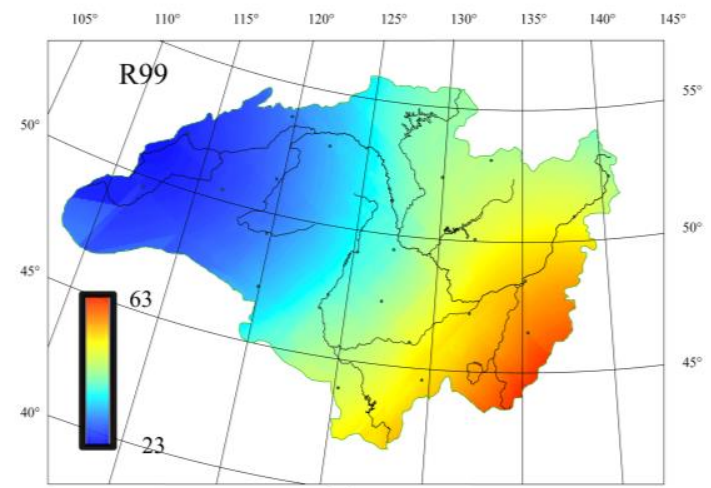

(e)

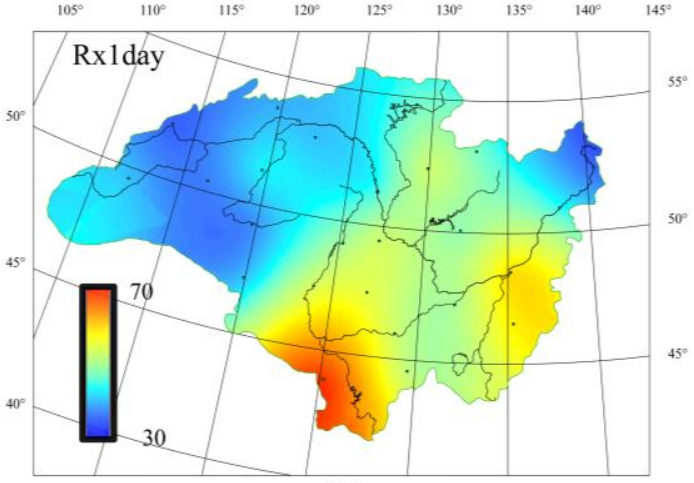

(b)

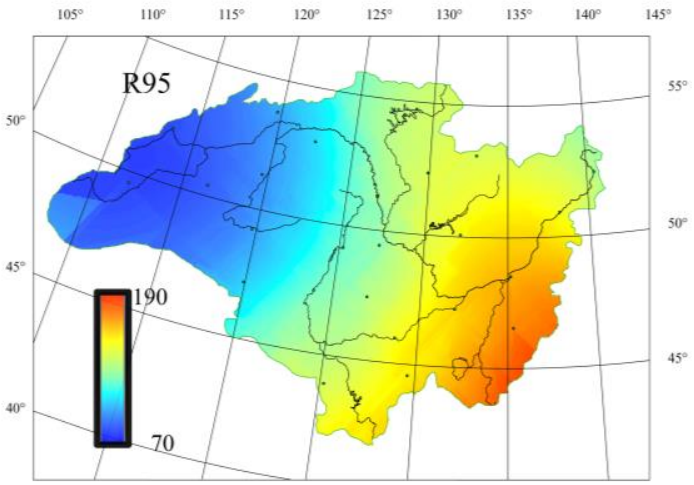

(d)

Figure 3. Spatial distribution for the multi-year mean of extreme precipitation indices from 1954 to 2014 in the Amur River basin (unit mm). (PRCPTOT-annual total wet-day precipitation, Rxlday-maximum 1-day precipitation amount, Rx5day-maximum 5-day precipitation amount, R95-very wet days, R99-extremely wet days)

\section{Trends of extreme precipitation indices}

For the five indices, the area-averaged trends are weak and statistical non-significant, the Kendall slopes for PRCPTOT, Rx1day, Rx5day, R95 and R99 are -0.28, 0.02, -0.04, 0.01 and $0.09 \mathrm{~mm} /$ year, respectively. For the spatial trends results (Fig. 4), only Nizhnetambovskoe station, the trends of Rx1day, Rx5day, R95 and R99 are notable and positive significantly, while the other stations fluctuate weakly in all indices during the study period. 

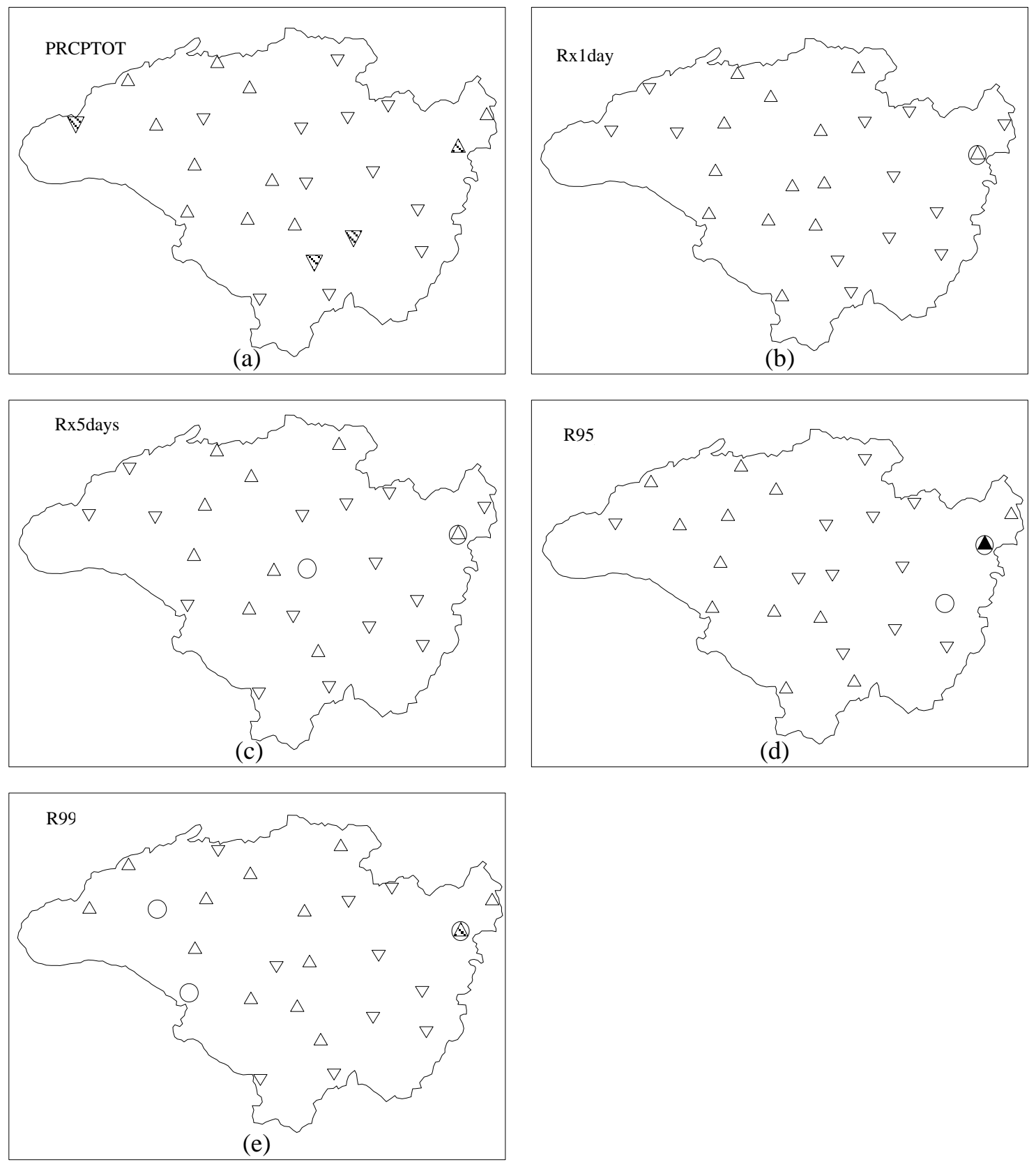

Figure 4. Spatial pattern of trends for the extreme precipitation indices for 25 stations from 1954 to 2014 in the Amur River basin $(\mathbf{\Lambda}, \triangle, \Delta, 0, \nabla, \nabla, \nabla$ indicate $\beta>2 \mathrm{~mm} /$ year, $1<\beta \leq 2 \mathrm{~mm} /$ year, $0<\beta \leq 1 \mathrm{~mm} /$ year, $\beta=0,-1<\beta<0 \mathrm{~mm} /$ year, $-2<\beta \leq-1 \mathrm{~mm} /$ year, $\beta \leq-$ $2 \mathrm{~mm} /$ year, respectively; the triangles that are rounded indicate significant trend at 0.05 level). (PRCPTOT-annual total wet-day precipitation, Rxlday-maximum 1-day precipitation amount, Rx5day-maximum 5-day precipitation amount, R95-very wet days, R99-extremely wet days)

\section{Periodicities of extreme precipitation indices}

Wavelet analysis is employed to judge the periodicities of the extreme precipitation indices. For PRCPTOT, three peaks can be found in the Periodicities diagnosis graphs of annual area-averaged indices series and they are located at time scale of 4, 13 and 29a. As the peak value means the oscillation strength, the first main period is $29 a$, and 
the second and third are 13 and $4 \mathrm{a}$ respectively. The main periods are 30, 19 and 5a for Rx1day, 30, 14 and 6a for Rx5day, 30, 13 and 4a for R95, and 28, 11, 18 and 6a for R99, respectively.

Figure 5 shows the wavelet transform real part variation course of annual areaaveraged indices series. The size of amplitude responses the periodic obviousness, and the amplitude of the first main period of 29a are larger than those of 13 and $4 \mathrm{a}$ in Figure 5a. For PRCPTOT, the amplitude of 13a time scale becomes gradually smaller in the entire study period, and even weaker than 4a after 1990. It reveals that the periodicity of 4a timescale was more obvious than 13a after 1990. Besides, the positive real part phase means abundant PRCPTOT, while the negative real part phase indicates scarce PRCPTOT. Taking 13a time scale as example, abundant PRCPTOT occurred in 1957-1962, 1969-1974, 1992-1998 and 2010-2014.

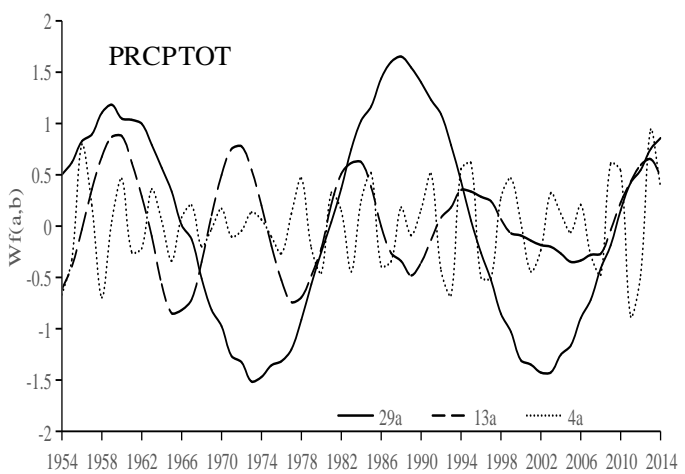

Time (a)

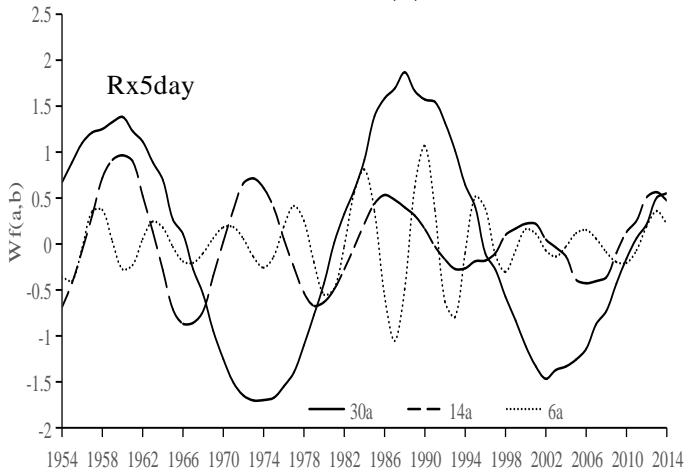

Time (c)

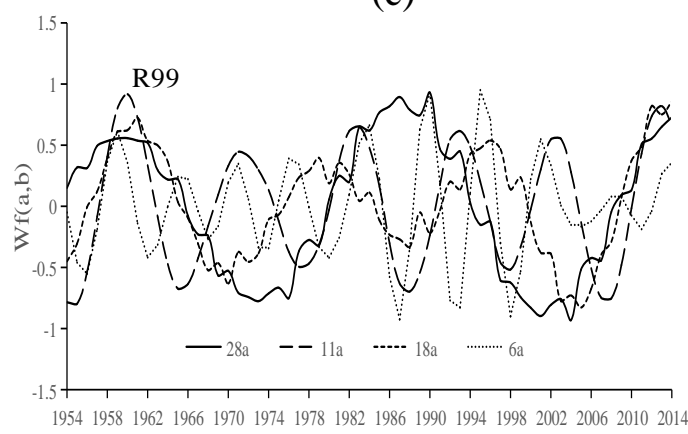

Time (e)

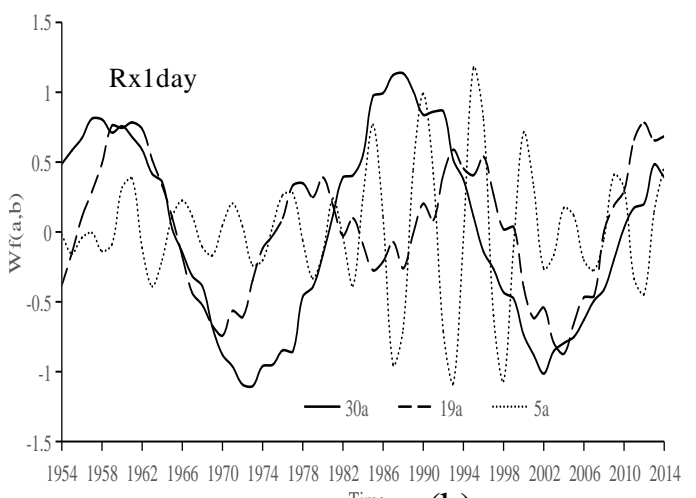

(b)

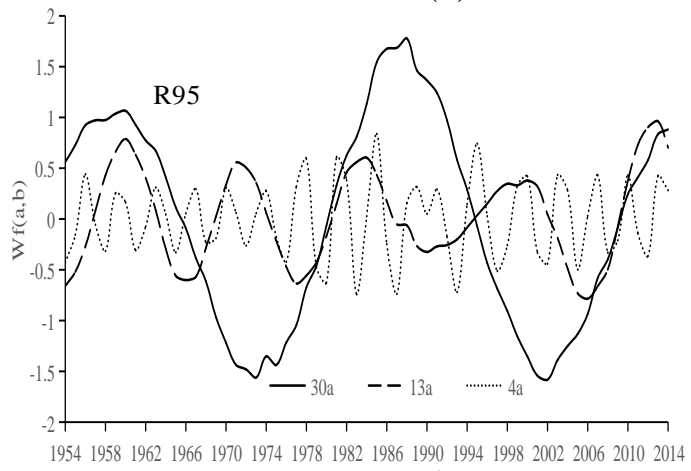

(d)

Figure 5. The wavelet transform real part variation course of annual area-averaged indices series (PRCPTOT-annual total wet-day precipitation, Rxlday-maximum 1-day precipitation amount, Rx5day-maximum 5-day precipitation amount, R95-very wet days, R99-extremely wet days) 
Overall, the periodicities analysis of the annual extreme precipitation indices explains the cause of the extreme precipitation in Amur River basin in 2013. For PRCPTOT, Rx1day, Rx5day, R95 and R99, the real part wavelet phase of main periods were mostly located at positive peaks in 2013.

\section{Abrupt changes of extreme precipitation indices}

The Mann-Kendall method is used to perform abrupt change testing on extreme precipitation indices, which is widely used in hydrometeorology. Figure 6 shows the Mann-Kendall abrupt change test of the five extreme precipitation indices from 1954 to 2014. It can be seen from the figure that there are similar abrupt change characteristics in the five extreme indices, with two change points around 1963 and around 1989. Both of these change points correspond to the peak of the first main period in Figure 5, which indicates that there is a certain relationship between the abrupt change and the periodic variation of the sequence. In addition, the lines of Rx1day, R95 and R99 have intersections in 2013, 2014 and 2012, respectively, while the other two indicators will intersect at the end of the evaluation period, which is almost the same as the peak of the first main period in Figure 5.

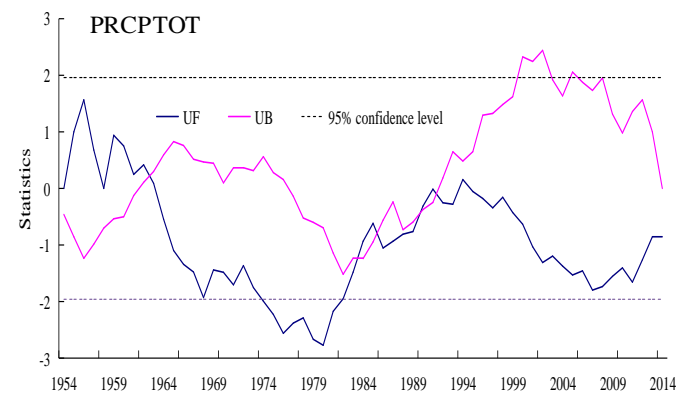

Year (a)
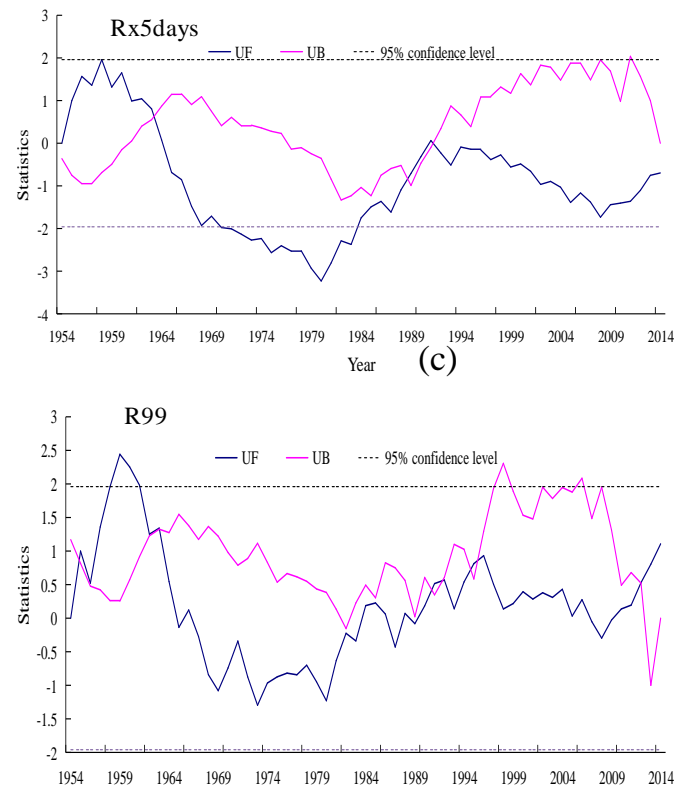

(e)

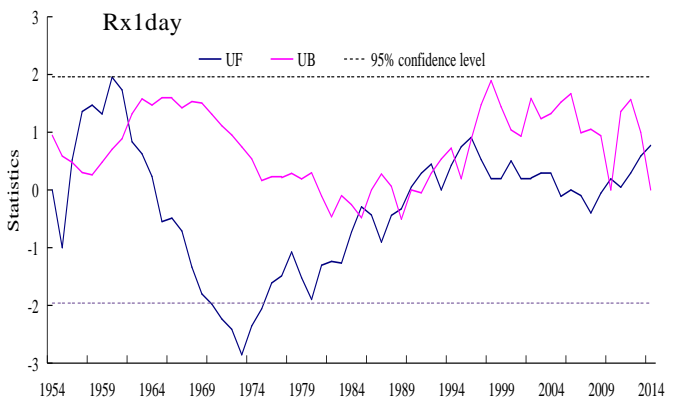

(b)

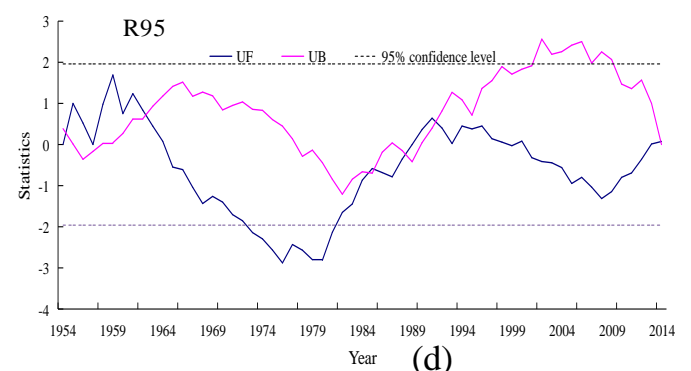

(d)

Figure 6. The Mann-Kendall abrupt change test of annual area-averaged indices series. (PRCPTOT-annual total wet-day precipitation, Rxlday-maximum 1-day precipitation amount, Rx5day-maximum 5-day precipitation amount, R95-very wet days, R99-extremely wet days) 


\section{Extreme precipitation analyses at typical stations in 2013 floods}

The Hailun and Hailar Stations received record-breaking observations of daily maximum precipitation in 2013. The GEV distribution was fitted to the annual Rx1day series of Hailun and Hailar, and the profile likelihood method was employed to estimate the 10/50/100-year return levels (Table 4). For Hailun station, the record-breaking data $(153.6 \mathrm{~mm})$ was around 100-year return level in the evaluation period of 1954-2012, and improve the 10/50/100-year return levels $(76.37,100.90$ and $111.47 \mathrm{~mm})$ to 89.14 , 114.62 and $130.61 \mathrm{~mm}$. For Hailar station, the record-breaking observation $(85.80 \mathrm{~mm})$ was also around 100-year return level in the period of 1954-2012, and the 10/50/100year return levels $(51.99,70.45$ and $78.95 \mathrm{~mm})$ were raised to $54.21,76.80$ and $87.91 \mathrm{~mm}$.

Table 4. The 10/50/100-year return levels and 0.95 confidence intervals (mm) estimated by the profile likelihood method for annual Rxlday series

\begin{tabular}{|c|c|c|c|c}
\hline Region & Time series & 10 years & 50 years & 100 years \\
\hline \multirow{2}{*}{ Hailun } & $1954-2012$ & $76.37(68.63,89.33)$ & $100.90(87.37,136.47)$ & $111.47(94.21,162.38)$ \\
\cline { 2 - 4 } & $1954-2013$ & $89.14(79.71,97.33)$ & $114.62(94.96,161.45)$ & $130.61(104.34,199.60)$ \\
\hline \multirow{2}{*}{ Hailar } & $1954-2012$ & $51.99(46.51,61.84)$ & $70.45(59.46,101.75)$ & $78.95(64.35,126.00)$ \\
\cline { 2 - 4 } & $1954-2013$ & $54.21(47.91,65.77)$ & $76.80(63.16,115.72)$ & $87.91(68.94,138.21)$ \\
\hline
\end{tabular}

This study analyzes the temporal and spatial variation characteristics of extreme precipitation indices for the trend, periodicity and abrupt change analysis of five extreme precipitation indices. The results of the trend, periodicity and abrupt change analysis are also mutually corroborated, indicating to some extent the correctness of the results of the analysis. This study has certain similarities with the results of other scholars studying Northeast Asia, but other scholars are limited by the availability of data, and the scope of research is limited to China (Deng et al., 2018; Liu et al., 2015) or Russia (Vyshkvarkova and Voskresenskaya, 2018). In addition, some scholars use large-scale meteorological products to analyze extreme precipitation (Zhu et al., 2018; Tao et al., 2018). Based on the analysis of spatio-temporal distribution characteristics of extreme precipitation, this paper uses GEV distribution to analyze the impact of the extremes on the return levels of typical stations by comparison two periods with or without the value of 2013, which is helpful to further understand the numerical value of the single extreme value for the entire evaluation period. Furthermore, the causes of extreme precipitation are not studied in this paper, and it is expected to be demonstrated in future research..

\section{Conclusions}

1. Generally, the changes of annual PRCPTOT, Rx1day, Rx5day, R95 and R99 series are almost consistent, while the R99 with the largest variation coefficient (0.30) fluctuate severely.

2. For PRCPTOT, Rx1day, Rx5day, R95 and R99 indices, not only area-averaged but also individual stations have weak and non-significant trends except for the Nizhnetambovskoe Station. 
3. It was reasonable to use wavelet analysis to explore the periodicities for annual PRCPTOT, Rx1day, Rx5day, R95 and R99 series, and the real part wavelet phase of main periods were mostly located at positive peaks in 2013. It means that the periodicities of the extreme precipitation indices are the main cause for 2013 extreme precipitation event than the trends.

4. The correlation coefficients among PRCPTOT, Rx1day, Rx5day, R95 and R99 varied from 0.50 to 0.84 , and all have passed 0.01 significant level.

5. The Hailun and Hailar stations suffered from record-breaking daily maximum precipitation in 2013, and their 10/50/100-year return levels were raised from 76.37/100.90/111.47 $\mathrm{mm}$ and 51.99/70.45/78.95 $\mathrm{mm}$ to $89.14 / 114.62 / 130.61 \mathrm{~mm}$ and $54.21 / 76.80 / 87.91 \mathrm{~mm}$, respectively.

Acknowledgements. This work is funded by the National Key R\&D Program of China (2017YFC0403600, 2017YFC0403606, 2017YFC1502404), National Public Research Institutes for Basic R\&D Operating Expenses Special Project (CKSF2017061/SZ, CKSF2017057/SZ, CKSF2017008), the National Natural Science Foundation of China (No. 51779013, 51509009), Water Conservancy Science and Technology Innovation project of GuangDong Province (2017-03). Special thanks are given to the anonymous reviewers and editors for their constructive comments.

\section{REFERENCES}

[1] Aguilar, E., Barry, A. A., Brunet, M., Ekang, L., Fernandes, A., Massoukina, M., Mbah, J., Mhanda, A. D., Nascimento, D., Peterson, T. (2009): Changes in temperature and precipitation extremes in western central Africa, Guinea Conakry, and Zimbabwe, 19552006. - Journal of Geophysical Research: Atmospheres (1984-2012) 114(D2).

[2] Ahmad, I., Tang, D., Wang, T., Wang, M., Wagan, B. (2015): Precipitation trends over time using Mann-Kendall and spearman's RHO tests in swat river basin, Pakistan. Advances in Meteorology. http://dx.doi.org/10.1155/2015/431860.

[3] Altinsoy, H., Ozturk, T., Turkes, M., Kurnaz, M. (2013): Simulating the Climatology of Extreme Events for the Central Asia Domain Using the RegCM 4.0 Regional Climate Model. - In: Helmis, C., Nastos, P. T. (eds.) Advances in Meteorology, Climatology and Atmospheric Physics. Springer, Berlin, Heidelberg, pp. 365-370.

[4] Bordi, I., Fraedrich, K., Petitta, M., Sutera, A. (2007): Extreme value analysis of wet and dry periods in Sicily. - Theoretical and Applied Climatology 87(1-4): 61-71.

[5] Burke, E. J., Perry, R. H. J., Brown, S. J. (2010): An extreme value analysis of UK drought and projections of change in the future. - Journal of Hydrology 388(1): 131-143.

[6] Changnon, S. A., Pielke, R. A., Changnon, D., Sylves, R. T., Pulwarty, R. (2000): Human factors explain the increased losses from weather and climate extremes. - Bulletin of the American Meteorological Society 81(3): 437-442.

[7] Dai, X., Wang, P., Chou, J. (2003): Multiscale characteristics of the rainy season rainfall and interdecadal decaying of summer monsoon in North China. - Chinese Science Bulletin 48(24): 2730-2734.

[8] Danilov-Danil'yan, V. I., Gel'fan, A. N. (2014): The extraordinary flood in the Amur River Basin. - Herald of the Russian Academy of Sciences 84(5): 335-343.

[9] Deflorio, M. J., Pierce, D. W., Cayan, D. R., Miller, A. J. (2013): Western US extreme precipitation events and their relation to ENSO and PDO in CCSM4. - Journal of Climate 26(12): 4231-4243.

[10] Deng, Y., Jiang, W., He, B., Chen, Z., Jia, K. (2018): Change in intensity and frequency of extreme precipitation and its possible teleconnection with large-scale climate index 
over the china from 1960 to 2015. - Journal of Geophysical Research Atmospheres 123(4).

[11] Easterling, D. R., Evans, J. L., Groisman, P. Y., Karl, T. R., Ambenje, P. (2000a): Observed variability and trends in extreme climate events: a brief review. - Bulletin of the American Meteorological Society 81(3): 417-425.

[12] Easterling, D. R., Meehl, G. A., Parmesan, C., Changnon, S. A., Karl, T. R., Mearns, L. O. (2000b): Climate extremes: observations, modeling, and impacts. - Science 289(5487): 2068-2074.

[13] Field, C., Barros, V., Stocker, T. et al. (2012): Managing the Risks of Extreme Events and Disasters to Advance Climate Change Adaptation. A Special Report of Working Groups I and II of the Intergovernmental Panel on Climate Change. - Cambridge University Press, New York.

[14] Fu, G., Yu, J., Yu, X., Ouyang, R., Zhang, Y., Wang, P., Liu, W., Min, L. (2013): Temporal variation of extreme rainfall events in China, 1961-2009. - Journal of Hydrology 487: 48-59.

[15] Furió, D., Meneu, V. (2011): Analysis of extreme temperatures for four sites across Peninsular Spain. - Theoretical and Applied Climatology 104(1-2): 83-99.

[16] Griggs, D. J., Noguer, M. (2002): the scientific basis. Contribution of working group I to the third assessment report of the intergovernmental panel on climate change. - Weather 57(8): 267-269.

[17] Huang, F., Xia, Z., Guo, L., Yang, F. (2013): Climate change detection and annual extreme temperature analysis of the Irtysh Basin. - Theoretical and Applied Climatology 111(3-4): 465-470.

[18] Katz, R. W.; Brown, B. G. (1992): Extreme events in a changing climate: variability is more important than averages - Climatic Change 21(3): 289-302.

[19] Kumar, K. R., Pant, G. B., Parthasarathy, B., Sontakke, N. A. (1992): Spatial and subseasonal patterns of the long-term trends of Indian summer monsoon rainfall. International Journal of Climatology 12(3): 257-268.

[20] Lau, K. M., Weng, H. (1995): Climate signal detection using wavelet transform: How to make a time series sing. - Bulletin of the American Meteorological Society 76(12): 23912402.

[21] Li, C., Walter, L. F., Wang, J., Hubert, F., Mariia, F., Hu, R., Yin, S., Bao, Y., Yu, S., Julian, H. (2018): An analysis of precipitation extremes in the inner mongolian plateau: spatial-temporal patterns, causes, and implications. - Atmosphere 9(8): 322.

[22] Li, J., Liu, B. (2006): The change character of monsoon rainband over Heilongjiang Province for the past 40 years. - Journal of Forestry Research 17(1): 71-74.

[23] Liu, B., Xiao, C., Liang, X. (2015): Evaluation of spatial and temporal characteristics of precipitation variations in Jilin Province, Northeast China. - Theoretical and Applied Climatology 122(1-2): 129-142.

[24] Liu, R., Liu, S., Cicerone, R., Shiu, C., Li, J., Wang, J., Zhang, Y. (2015): Trends of extreme precipitation in eastern China and their possible causes. - Advances in Atmospheric Sciences 32(8): 1027-1037.

[25] Minetti, J. L., Vargas, W. M., Poblete, A., Acuña, L., Casagrande, G. (2003): Non-linear trends and low frequency oscillations in annual precipitation over Argentina and Chile, 1931-1999. - Atmósfera 16(2): 119-135.

[26] Moonen, A. C., Ercoli, L., Mariotti, M., Masoni, A. (2002): Climate change in Italy indicated by agrometeorological indices over 122 years. - Agricultural and Forest Meteorology 111(1): 13-27.

[27] Nicholson, U., Poynter, S., Clift, P. D., Macdonald, D. I. M. (2014): Tying catchment to basin in a giant sediment routing system: a source-to-sink study of the Neogene-Recent Amur River and its delta in the North Sakhalin Basin. - Geological Society, London, Special Publications 386(1): 163-193. 
[28] Preethi, B., Revadekar, J. V., Munot, A. A. (2011): Extremes in summer monsoon precipitation over India during 2001-2009 using CPC high-resolution data - International Journal of Remote Sensing 32(3): 717-735.

[29] Qian, W., Zhu, Y. (2001): Climate change in China from 1880 to 1998 and its impact on the environmental condition. - Climatic Change 50(4): 419-444.

[30] Revadekar, J., Preethi, B. (2012): Statistical analysis of the relationship between summer monsoon precipitation extremes and foodgrain yield over India. - International Journal of Climatology 32(3): 419-429.

[31] S. M. Allen, Gough, W. A., Mohsin, T. (2015): Changes in the frequency of extreme temperature records for Toronto, Ontario, Canada. - Theoretical and Applied Climatology 119(3-4): 481-491.

[32] Scaife, A. A., Folland, C. K., Alexander, L. V., Moberg, A., Knight, J. R. (2008): European climate extremes and the North Atlantic Oscillation. - Journal of Climate 21(1): 72-83.

[33] Semenov, E. K., Sokolikhina, N. N., Tatarinovich, E. V., Tudrii, K. O. (2014): Synoptic conditions of the formation of a catastrophic flood on the Amur River in 2013. - Russian Meteorology and Hydrology 39(8): 521-527.

[34] Shi, Y., Shen, Y., Kang, E., Li, D., Ding, Y., Zhang, G., Hu, R. (2007): Recent and future climate change in Northwest China. - Climatic Change 80(3-4): 379-393.

[35] Tabari, H. Talaee, P. H. (2011): Temporal variability of precipitation over Iran: 19662005. - Journal of Hydrology 396(3): 313-320.

[36] Tao, Y., Wang, W., Song, S., Ma, J. (2018): Spatial and temporal variations of precipitation extremes and seasonality over China from 1961 2013. - Water 10(6): 719.

[37] Trenberth, K. E. (1999): Conceptual Framework for Changes of Extremes of the Hydrological Cycle with Climate Change. - In: Karl, T. R. et al. (eds.) Weather and Climate Extremes. Springer, Dordrecht, pp. 327-339.

[38] Turner, A. G., Slingo, J. M. (2009): Uncertainties in future projections of extreme precipitation in the Indian monsoon region. - Atmospheric Science Letters 10(3): 152158.

[39] Vyshkvarkova, E. V., Voskresenskaya, E. N. (2018): Changes of extreme precipitation in Southern Russia. - IOP Conference Series: Earth \& Environmental Science 107(1): 012044.

[40] Wang, X., Wang, T., Yang, M., Zhang, N., Lu, D., Xu, T. (2018): Temporal and spatial distribution characteristics of surface vapor pressure and their influencing factors in Weifang. - Journal of Meteorology \& Environment 34(3): 78-85.

[41] Wang, X. L. (2008a): Accounting for autocorrelation in detecting mean shifts in climate data series using the penalized maximal t or F test. - Journal of Applied Meteorology and Climatology 47(9): 2423-2444.

[42] Wang, X. L. (2008b): Penalized maximal F test for detecting undocumented mean shift without trend change. - Journal of Atmospheric and Oceanic Technology 25(3): 368-384.

[43] Wang, X. L., Feng, Y. (2013): RHtestsV4 User Manual. - Climate Research Division, ASTD, STB, Environment Canada.

[44] Wang, Y., Zhou, L. (2005): Observed trends in extreme precipitation events in China during 1961-2001 and the associated changes in large-scale circulation. - Geophysical Research Letters 32(9).

[45] Yin, J., Yan, D., Yang, Z., Yuan, Z., Yuan, Y., Wang, H., Shi, X. (2016): Research on historical and future spatial-temporal variability of precipitation in China. - Advances in Meteorology. http://dx.doi.org/10.1155/2016/9137201.

[46] You, C. H., Lee, D. I., Kang, M. Y. (2014): Rainfall estimation using specific differential phase for the first operational polarimetric radar in Korea. - Advances in Meteorology. http://dx.doi.org/10.1155/2014/413717.

[47] Yu, L., Xia, Z., Li, J., Cai., T. (2013): Climate change characteristics of Amur River. Water Science and Engineering 6(2): 131-144. 
[48] Yue, S., Pilon, P., Cavadias, G. (2002): Power of the Mann-Kendall and Spearman's RHO tests for detecting monotonic trends in hydrological series. - Journal of Hydrology 259(1): 254-271.

[49] Zhu, J., Huang, G., Wang, X., Cheng, G., Wu, Y. (2018): High-resolution projections of mean and extreme precipitations over china through PRECIS under RCPs. - Climate Dynamics 50(11-12): 4037-4060. 